\title{
Close Contact: An Examination Of The Future Of Near Field Communications
}

\author{
Chris Rose, Capella University, USA
}

\begin{abstract}
Payment systems are changing and credit cards might soon be obsolete. Near field communications systems are being built into many smartphones which will enable users to not only pay for goods and services but to obtain information from NFC-enables products. Some emerging technologies are examined and potential security concerns are outlined.
\end{abstract}

\section{INTRODUCTION}

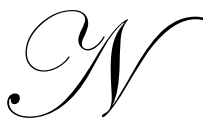

ear Field Communication (NFC) is a short-range wireless technology that allows NFC equipped devices to exchange small amounts of data if they are touching or within approximately 1.6 inches of each other. The name NFC "derives from the inductive effect of the "near field," i.e., within two wave-lengths distance, of the antenna" (Murray, 2011). This data can include credit card information, train or airline tickets, coupons or information about products or services. However, both the sending and receiving device must be specially equipped with NFC to participate. This type of technology isn't new as such, since it shares the same basic technology with RFID tags and contactless smartcards. Currently very few smartphones are equipped with NFC technology (it is enabled as read-only in the Google nexus S) but the NFC tags are extremely inexpensive and can be embedded in almost anything, such as glass, posters, stickers etc. Although not prevalent in the USA, it is already being used extensively in Japan for train tickets and as a contactless payment system at some retailers (Gardiner, 2010).

The decision by Google to officially end support for QR codes (those 2D barcodes that can be read by camera-equipped phones) might be one reason to believe that NFC is about to go mainstream. In fact, Google has even recently joined the NFC non-profit association as a new member with voting privileges and is now testing its Hotpot program, a service that encourages customers to review and rate their local businesses. Google provided Hotpot merchants in Portland, Oregon with NFC-equipped window decals which when tapped or in close proximity to a NFC phone would link to their Google Places page (Perez, 2011).

\section{NFC USES}

Payments is only one use of NFC, it can both read to and send from so you could for example, touch a poster and find out more information about a subject and later use the very same device to purchase a train ticket. It could get you into a concert or football game after you bought a ticket online so it could actually link your online and real-world social life (Branscombe, 2011). One obvious consumer use of NFC would be the pairing of devices such as Wi-Fi routers or Bluetooth devices where instead of the current process of exchanging small pieces of information between two devices, the devices are simply touched together and pairing would be automatic since they would instantly exchange data.

But others do not believe that NFC adoption is near and that it won't soon be a common sight to see people waving smartphones to pay for subway fares or retail purchases in the USA because of slow adoption of the reader terminals. Although there are about 150,000 NFC retail terminals in the USA, those terminals are several years old and would have to be replaced with models that are capable of collecting information on customers' buying habits (Hamblen, 2011b). The good news is that the dominant Point of Sale company, Verifone, is to include near field communication technology in all its new point-of-sale hardware. This is a major step towards widespread adoption of NFC since any merchant upgrading their terminal will automatically now have the ability to process contactless 
and NFC payments, and they wouldn't have to pay extra for the technology (Brown, 2011).

Amazon is also said to be implementing NFC payments with the introduction of a service that would let shoppers pay for purchases at stores using their mobile phones. Apple is also rumored to be starting a loyalty program, and Google intends to sell targeted advertisements and discounts to merchants. "One of the possibilities is the ability to find additional stock on Amazon if, for example, the store you're in does not have your own size in stock. This would be done by tapping your phone against an item's NFC tag to locate it on Amazon" (McEntegart, 2011).

Apple is also reported to have interest in NFC and this is seen by some as a possible boost to the technology, because if iPads and iPhones were equipped with NFC, this could bring millions of iTunes users into the NFC market. If Apple was able to establish this system this would mean that if people pay for NFC-enabled transactions using money in their iTunes accounts, this would "exclude banks, credit card companies and other financial services firms from the payment loop. An iTunes-based setup could also potentially diminish the role played by wireless carriers, who might otherwise act as billing agents when phones are used to make payments" (Hamblen, 2011a). Apple's main goal would be to get a piece of the $\$ 6.2$ trillion Americans spend each year on goods and services, Instead of paying credit-card processing fees on every purchase from iTunes, Apple could encourage users to use NFC which is directly connected to their bank account, similar to how many payments are now done on PayPal, which would cut costs for both Apple and retailers selling Apple products (Biggs, 2011).

In 2008, Deutsche Bahn, the German rail operator, launched a pilot program that allowed 200 people to touch their phones to a NFC contact whenever they boarded or left the train. The program was so successful that in January 2010 they added another 3,000 travelers (Kessler, 2010). In the medical field NFC could also provide information about what treatment a patient received, when and by what doctors and nurses. In Oulu, Finland, the city installed about 1,500 "infotags" in buses and at bus stops, in theaters, a restaurants, and pubs, that could be read with a smartphone. For example, at the theatre the phone could be used as tickets or to order refreshments, but they could also be touched to a poster and more information about the play could be transferred. Infotags were also installed in schools so students could each get announcements and their individual daily schedule and information about homework by waving their phones past the tags. NFC may have similar applications as bar codes do now but so much more can be done because you can always add more information about any product by adding a NFC tag. In fact, a "company called Objecs, for instance, sells an NFC tablet for gravestones. Touching an NFC-enabled phone to the Personal Rosetta Stone provides additional information about the deceased" (Kessler, 2010). NFC may also be used for "swapping data from phone to phone or, for example, taking pictures from a phone and putting them on a TV. Nokia is believed to be bringing out an NFC-enabled version of the popular game Angry Birds later this year" (Cellan-Jones, 2011).

With NFC you can tell anything you interact with who you are. Therefore a poster on the subway or an ad in a magazine can connect you with offers and special promotions that are directly tailored to you-just by tapping them with your phone. Waiting in lines or getting stopped by gatekeepers could be a thing of the past since an NFC reader at the entrance to any event that needs a ticket could be now accessed with your phone. Since your ticket information is stored electronically you could just wave your phone and enter. There would be no need to open an app to check into a place, and you could just tap your phone to share contact information with someone you have just met, "just hold your phones close and get the option to swap phone numbers, calendars, music, and more. Applications for NFC aren't all high tech: the protocol can be used for something as simple as unlocking doors. With your phone as your access key, you could simply tap it to your car or office door and quickly get inside-no fumbling through a key ring required" (Ugwu, 2011).

\section{DIGITAL WALLET}

NFC will most likely work with a digital wallet since it is not just about the hardware, there has to be software that enables the NFC system to work. NFC phones will come with a preinstalled mobile application that the user will need to activate and link to a credit card. AT\&T, T-Mobile, and Verizon are working to develop a mobile payment system, scheduled for deployment sometime in 2012 to provide an entire digital wallet to eliminate the need to "carry cash, credit and debit cards, reward cards, coupons, tickets, and transit passes" (Ogg, 2011). Google 
has been working with MasterCard and Citibank to plan for Android phones to be linked with their credit or debit cards. However, Google "is reportedly interested in taking the information gathered via payments made to brick and mortar retailers via NFC and selling ads against it, similar to how the company aims ads at people based on Google searches or Gmail messages"(Ogg, 2011).

There is one major problem to NFC adoption in the USA and that is the issue of transfer fees collected by banks, which have traditionally relied on a successful and well-established credit card system. However, AT\&T Mobility, Verizon Wireless and T-Mobile USA have formed a joint venture called ISIS that is working with Barclays' Barclaycard US unit to expand the use of NFC technology in the U.S. (Hamblen, 2011a)

A possibility is that your bank could itself ship some sort of complete mobile wallet system as a part of their mobile banking/mobile payments product. This mobile wallet could work together with the bank-provided, NFC-enabled debit and credit "cards" you use on your NFC-enabled mobile phone. This would not just be an app on an app on a phone, instead the digital wallet would:

actually consists of both the user interface itself and the secure element chip on the phone where your personal data (your credit card number, passport ID, shopping history, coupons, etc.) is stored. The user interface allows you to interact with NFC applications and with the secure data stored on the secure element on your device. A third part of the solution is the antenna, which is the piece that makes the near field communication possible. It's the secure element on the phone that's the most important part to the mobile wallet, though, and it's why the wallet isn't just "another app. (Perez, 2011a)

In the UK, the first digital wallet service has been launched and among shops signed up to the system are McDonalds, EAT, Pret-a-Manger and some Boots stores. It is called Quick Tap and is a collaboration between Orange and Barclaycard. Only purchases up to a value of $£ 15$ can be made using the service but users can preload their mobile with up to $£ 100$ (Cellan-Jones, 2011)

\section{SECURITY}

Although NFC is supposed to operate at a distance of less than 1.6 inches, there is concern that it could be tricked or coerced to operate at greater distance. For example, although standard Wi-Fi is supposed to work within a distance of a few hundred feet at the most, persons have extended the range to many miles and currently the longest distance recorded is 237 miles (Patel, 2007). If something that was supposed to operate at a distance of feet is now able to work at a distance of miles, what if NFC that is supposed to work within 1.6 inches is made to operate at a distance of 10 or 20 feet. In fact, there is a reliance on the near-field effect of the technology to limit "its effective range to about 1.6 inches but the "far field" effect of the antenna might leak information beyond the effective range, perhaps at a distance of a few meters". NFC like, Bluetooth, is very low power so electronic jamming will be extremely easy but this will depend largely "on the devices on which they are implemented, that is, in the ability of those devices and their operating system software to resist application-to-application data leakage and interference" (Murray, 2011).

Unlike Bluetooth, NFC does not provide encryption, and it is relatively low speed theoretically at $421 \mathrm{kbps}$ so it would be much too slow for many applications such as streaming video or even surfing the web but one great advantage it does have is connection time. While Bluetooth will take seconds to establish a connection, NFC takes less than a tenth of a second. This quick connection ability might also be a security problem since it might also be possible for a hacker to run wires beneath a long-sleeved shirt leading to NFC contacts and instead of physically picking your pocket he could touch your smartphone and pick your digital pocket by retrieving your data while in any crowded location.

\section{BLACKBERRY}

All future BlackBerry phones, made by the Canadian company Research in Motion (RIM) will be equipped with NFC and although they are not the first phones to be so equipped, it is believed that BlackBerry will lead in the acceptance of NFC within smartphones for mainly one reason; the BlackBerry platform is secure. Unlike other 
smartphones a BlackBerry does not directly connect with the Internet, it only connects indirectly through the BlackBerry Network Operations Center (NOC). If a Blackberry user opens a browser and goes to a web site, that information is passed to the NOC and the NOC then retrieves the Internet information, encrypts it and then sends it encrypted to the BlackBerry user. It is the only totally encrypted smartphone system and the user can even encrypt the media card which internally stores information. It is because of this encryption process that BlackBerry has had problems with the governments of Dubai, India, Saudi Arabia among others, because it is impossible to intercept BlackBerry communications without the assistance of the BlackBerry NOC but these governments wanted access to the phone communications within their country (Walid \& Karam, 2010).

Another reason BlackBerry might lead in NFC is simply because of battery life. Nobody will be willing to depend on their smartphone to pay for their train ride home late at night if they can't be sure that their battery can still power their phone. All other smartphones have battery life measured in hours but BlackBerry phones usually last days. In addition, some such as the iPhone, do not even have the ability to replace a battery so it would be impossible to carry a spare battery and replace a dying battery during the day. This would not inspire confidence in the user to depend on NFC as their payment system.

One other feature unique to Blackberry is the Blackberry messenger, a proprietary encrypted system that runs through the Blackberry servers providing secure, instantaneous two-way communication. Unlike other messaging systems where the receiver can claim they didn't receive the message, the BlackBerry messaging system confirms when the recipient receives a message, they can't deny it. This Blackberry Messenger system can be used by NFC to provide proof of mobile payment. "BBM is a real-time handshaking technology that confirms when I've sent something to you and when you've received it; in layman's terms that's called a receipt" (Jon, 2011). " What BlackBerry has is battery life that keeps going so you can still pay for things late in the evening, security that users, banks, mobile operators and companies who want to sell you something all trust - and good relationships with a lot of them already" (Branscombe, 2011).

\section{CONCLUSION}

The UK is adopting NFC payments at an accelerated rate and it is estimated that 40,000 businesses could be using (NFC) by the end of 2011. It is believed this will be boosted, in London by the 2012 Olympics since already there are some 60,000 sites in London that accept NFC payments, and there will be increasing efforts to increase that number as London 2012 nears. Samsung and Visa are working together on boosting London's NFC capabilities ahead of the Olympics but no consumer payment system will be readily accepted until it is at least as secure as existing methods. MasterCard's Edward Chandler claims that NFC is as secure as any credit or debit card is today (Jon, 2011).

This might be so since the system back-end might be as secure as it needs to be, but the front-end, the actual phones that implement the NFC system would have to have a much stronger security system and a much better battery life before it will be accepted. Nobody will go to a train station to buy a ticket with their NFC phone if they have to first plug in their charger and charge their phone before the purchase. Nobody will use it if when you claim to have paid, the vendor says it was not received. This just might be an opening for BlackBerry with their strong encryption, their security focus, long battery life and BlackBerry messenger which is guaranteed to have a record of every transaction. Once all these factors are in place, NFC will provide convenience and added benefit for both the consumer and retailer.

\section{AUTHOR INFORMATION}

Chris Rose, Capella University. E-mail: drcerose@gmail.com 


\section{REFERENCES}

1. Biggs, J. (2011) So Why Should You Care About NFC? Crunch Gear. Retrieved 5/3/2011 from http://www.crunchgear.com/2011/01/25/so-why-should-you-care-about-nfc/

2. Branscombe, M.(2011)How BlackBerry will bring mobile payments to the UK . Retrieved 5/5/2011 from http://www.techradar.com/news/phone-and-communications/mobile-phones/how-blackberry-will-bringmobile-payments-to-the-uk-952530\#ixzz1MSp2Mt48

3. Brown, C. (2011) Verifone to include NFC in all new POS terminals. Near Field Communications World. Retrieved 5/2/2011 from http://www.nearfieldcommunicationsworld.com/2011/03/03/36359/verifone-toinclude-nfc-in-all-new-pos-terminals/

4. Cellan-Jones, R. (2011) Mobile wallet offered to UK shoppers. BBC.com. Retrieved 5/20/2011 from http://www.bbc.co.uk/news/technology-13457071

5. Gardiner, B. (2010). What Is Near-Field Communication? Gizmodo. Retrieved 5/1/2011 from http://gizmodo.com/5707321/what-is-near+field-communication

6. Hamblen, M. (2011a). NFC: What you need to know. Computerworld. Retrieved 5/1/2011 from http://www.computerworld.com/s/article/9206919/NFC What you need to know

7. Hamblen, M. (2011b). Most NFC mobile wallet talk is 'half-baked,' analyst says. Computerworld. Retrieved 5/1/2011 from http://www.computerworld.com/s/article/9215555/Most_NFC_mobile_wallet talk_is half_baked_analyst $\underline{\text { says }}$

8. Jon (2011) BlackBerry Bold 9900 mobile payments become reality. Fone Home. retrieved 5/11/2011 from http://www.fonehome.co.uk/2011/05/10/blackberry-bold-9900-mobile-payments-become-reality/

9. $\quad$ Kessler, S (2011). NFC Technology: 6 Ways It Could Change Our Daily Lives. Mashable. Retrieved 5/8/2011 from http://mashable.com/2010/05/06/near-field-communication/

10. McEntegart, J. ( 2011) Amazon Exploring NFC Payments System. TomsGuide. Retrieved 5/1/2011 from http://www.tomsguide.com/us/Amazon-Mobile-Payments-NFC-Near-Field-Communication-wave-andpay,news-10715.html

11. Murray, W. (2011) Near Field Communication (NFC). Thinking about Security. Retrieved 5/3/ 2011 from http://whmurray.blogspot.com/2011/04/near-field-communication-nfc.html

12. Ogg, E. (2011) How mobile payments will work (FAQ). CNet News. Retrieved 5/2/2011 from http://news.cnet.com/8301-31021_3-20051474-260.html\#ixzz1MMxw9lt7

13. Patel, N. (2007) Venezuelans set new WiFi distance record: 237 miles Engadget. http://www.engadget.com/2007/06/19/venezuelans-set-new-wifi-distance-record-237-miles/

14. Perez, S. (2011a) NFC in 2011: Who's Building Your Mobile Wallet? ReadWriteWeb. Retrieved 5/1/2011 from http://www.readwriteweb.com/mobile/2011/03/nfc-in-2011-whos-building-your-mobile-wallet.php

15. Perez, S. (2011b) Google Ditches Barcodes for NFC. Read Write Web. Retrieved 5/1/2011 from http://www.readwriteweb.com/archives/Google_Joins_NFC_Forum_Ditches_QR_Codes.php

16. Raphael, J. 92010) What Google's NFC Android Phones Will Mean For You. PC World. Retrieved $5 / 2 / 2011$ from http://www.pcworld.com/article/210861/what_googles_nfc_android_phones_will_mean_for_you.html

17. Ugwu, R. (2011) Oh So Close: 5 Reasons to Get Excited for Near Field Communication. Complex Tech. Retrieved 5/1/2011 from http://www.complex.com/tech/2011/04/oh-so-close-5-reasons-to-get-excited-fornear-field-communicatioins/1-electronic-keys\#gallery

18. Walid T and Karam, S. (2010) BlackBerry users in UAE, Saudi may have services cut. reuters. retrieved 5/11/2011 from http://www.reuters.com/article/2010/08/01/us-uae-blackberry-idUSTRE6700C920100801

19. Wortham, J. (2011) Near-Field Communication: Beyond Mobile Transactions. The New York Times. Retrieved 5/4/ 2011 from http://bits.blogs.nytimes.com/2011/02/15/near-field-communication-beyondmobile-transactions/ 
\begin{tabular}{ll} 
International Journal of Management \& Information Systems - First Quarter $2012 \quad$ Volume 16, Number 1 \\
\hline
\end{tabular} NOTES 